\title{
Arsenic trioxide exposure impairs testicular morphology in adult male mice and consequent fetus viability
}

\author{
Raquel Frenedoso da Silva, Cibele dos Santos Borges, Celina de Almeida \\ Lamas, Valéria Helena Alves Cagnon \& Wilma de Grava Kempinas
}

To cite this article: Raquel Frenedoso da Silva, Cibele dos Santos Borges, Celina de Almeida Lamas, Valéria Helena Alves Cagnon \& Wilma de Grava Kempinas (2017) Arsenic trioxide exposure impairs testicular morphology in adult male mice and consequent fetus viability, Journal of Toxicology and Environmental Health, Part A, 80:19-21, 1166-1179, DOI: 10.1080/15287394.2017.1376405

To link to this article: https://doi.org/10.1080/15287394.2017.1376405

\section{曲 Published online: 28 Sep 2017.}

\section{Submit your article to this journal $\square$}

山 Article views: 85

View Crossmark data ¿

Citing articles: 8 View citing articles $\sqsubset$ 


\title{
Arsenic trioxide exposure impairs testicular morphology in adult male mice and consequent fetus viability
}

\author{
Raquel Frenedoso da Silva ${ }^{a}$, Cibele dos Santos Borges ${ }^{b}$, Celina de Almeida Lamas ${ }^{a}$, Valéria Helena Alves Cagnon , \\ and Wilma de Grava Kempinas ${ }^{\mathrm{b}}$ \\ aDepartment of Structural and Functional Biology, Institute of Biology, University of Campinas (UNICAMP), Campinas, SP, Brazil; bDepartment \\ of Morphology, Institute of Biosciences, Univ Estadual Paulista (UNESP), Botucatu, SP, Brazil
}

\begin{abstract}
The acute promyelocytic leukemia (APL) is a rare disease, affecting $0.1 / 100,000$ individuals globally. Despite significant advances in APL therapy, some patients still experience relapsed disease. Currently, arsenic trioxide $\left(\mathrm{As}_{2} \mathrm{O}_{3}\right)$ was found to be effective in relapsed APL treatment and considered as standard treatment for these cases. However, it has been shown that exposure to $\mathrm{As}_{2} \mathrm{O}_{3}$ may exert adverse effects on the male reproductive system since this substance might also induce apoptosis of other important cell types including stem cells. Studies demonstrated that treatment with this metallic substance decreased plasma levels of testosterone and interfered with sperm parameters such as concentration, motility, and viability. In addition, $\mathrm{As}_{2} \mathrm{O}_{3}$ was found to produce significant damage to spermatocytes, which may be associated with testicular toxicity and consequent inhibition of spermatogenesis. The aim of this study was to determine subchronic treatment effects of $\mathrm{As}_{2} \mathrm{O}_{3}$ on sperm and testicular morphology, androgen receptor (AR) immunoreactivity in testes and epididymis, in addition to evaluation of fertility parameters in adult male mice. Thirty adult Swiss mice were divided into three experimental groups: control; received distilled water (vehicle) while treated received 0.3 or $3 \mathrm{mg} / \mathrm{kg} / \mathrm{day} \mathrm{As}_{2} \mathrm{O}_{3}$ subcutaneously, for 5 days per week, followed by 2 days of interruption, for 5 weeks. Results showed that $\mathrm{As}_{2} \mathrm{O}_{3}$ (1) decreased spermatozoa number, (2) produced seminiferous epithelium degeneration and exfoliation of germ cells tubule lumen (3) altered nucleus/cytoplasm proportion of Leydig cells and (4) reduced $A R$ immunoreactivity in both Leydig and epithelial epididymal cells. Further, fetal viability tests demonstrated an increase in post-implantation loss in females that were mated with $\mathrm{As}_{2} \mathrm{O}_{3}$ treated males. Data indicate that $\mathrm{As}_{2} \mathrm{O}_{3}$ exposure altered the spermatogenic process and subsequently fetal viability.
\end{abstract}

\section{KEYWORDS}

Arsenic trioxide; sperm malformation; post-implantation loss; androgen receptor; toxicology

\section{Introduction}

Arsenic (As) is a widely trace metal present in the environment, characterizing it as an environmental contaminant whose exposure is considered a significant concern for global health due to vascular, ocular, dermal, carcinogenic, and mutagenic effects (Bernstam and Nriagu 2000; Golub, Macintosh, and Baumrind 1998; Kleiman et al. 2016; Li et al. 2012; Morales-Marin et al. 2015; Tsai, Wang, and Ko 1998). However, in 1970, researchers discovered the effectiveness of an Asbased drug in the treatment of acute promyelocytic leukemia (APL), capable of promoting complete remission in some cases (Chen et al. 1997). Since then, several studies demonstrated the efficacy of chemotherapy with arsenic trioxide $\left(\mathrm{As}_{2} \mathrm{O}_{3}\right)$ (Shen et al. 1997; Soignet et al. 1998, 2001; Mathews et al. $2006,2011)$. The estimated incidence of APL among population is $0.1 / 100,000$ affecting mainly male young patients (77\%, between 21 and 40 years of age), which is considered a rare disease (Cicconi and Lo-Coco 2016; Shah et al. 2012). The Latino-American population represents the major proportion of affected population (Testi et al. 2014). Despite the advances in APL therapy, 20\% of patients present relapsed disease, and for these patients $\mathrm{As}_{2} \mathrm{O}_{3}$ was found to be the standard treatment (Yanada et al. 2017).

Arsenic trioxide is involved in several mechanistic pathways against malignant carcinoma cells, and its mechanism of action is dose-dependent:

CONTACT Raquel Frenedoso da Silva raquelfrenedoso@yahoo.com.br University of Campinas (UNICAMP), Campinas, São Paulo 13083865, Brazil.

Color versions of one or more of the figures in the article can be found online at www.tandfonline.com/uteh.

๑) 2017 Taylor \& Francis 
low concentrations induce cell differentiation, whereas high concentrations induce apoptosis. Apoptosis is induced by caspases cascade activation, decreased mitochondrial membrane potential, and production of reactive oxygen species (ROS) due to oxidation of reduced glutathione. Since ROS is known to play role in DNA and tissue damage, $\mathrm{As}_{2} \mathrm{O}_{3}$ exposure has been correlated to intrinsic mitochondrial-mediated apoptosis (Fan et al. 2016; King et al. 2016; Zhang et al. 2015). Further, downregulation of Bcl-2, an antiapoptotic protein, produced cell cycle arrest and disrupted cell proliferation (Emadi and Gore 2010; Qin, Huang, and Wu 2008).

However, despite the significant usage and proven effectiveness in the treatment of APL and other cancer types such as hepatocellular carcinoma and lung cancer ( $\mathrm{Hu}$ et al. 2016; Walker et al. 2016), it is important to perform risk assessment and benefit determination due to the side effects of this drug since it is known that exposure to $\mathrm{As}_{2} \mathrm{O}_{3}$ may exert adverse effects on male reproductive system (da Silva et al. 2016), and administration of As-containing substances may also induce apoptosis in other important cell types including stem cells.

Studies demonstrated that treatment with Ascontaining substances decreased plasma levels of testosterone and interfered with sperm parameters such as concentration, motility, and viability. In addition, significant damage to spermatocyte, which may be associated with testicular toxicity and consequent inhibition of spermatogenesis, was reported (Chiou et al. 2008; Golub, Macintosh, and Baumrind 1998; Nava-Hernandez et al. 2009; Souza et al. 2016). However, the precise morphological changes that occur in reproductive organs of animals exposed to As-containing substances that lead to loss of fertility potential and reduced fetal viability remain to be determined.

Based upon findings thus far, it was postulated that exposure to $\mathrm{As}_{2} \mathrm{O}_{3}$ comparable to doses used in human chemotherapy might induce testicular damage leading to sperm malformations and alterations in androgen receptor (AR) immunoreactivity with consequent impact on fertility of exposed individuals. Thus, the objective of this investigation was to examine influence of subchronic treatment with $\mathrm{As}_{2} \mathrm{O}_{3}$ on sperm and testicular morphology, AR immunoreactivity in testis and epididymis. In addition, evaluation of fertility parameters of adult male mice exposed to the drug was also undertaken.

\section{Materials and methods}

\section{Animals and treatment}

Thirty adult Swiss male mice (SPF) 70 days of age, weighing 30-40 g, supplied by the Multidisciplinary Center for Biological Investigation, State University of Campinas, were used in this study. Procedures were approved by the Ethics Committee for the Use of Experimental Animals from UNESP - Univ Estadual Paulista, Brazil (protocol number: 429). Animals were maintained in a controlled environment with temperature at $\pm 23^{\circ} \mathrm{C}$, humidity of $55 \% \pm 5 \%$, and $12 \mathrm{~h}$ light/dark cycle (lights on 7:00 a.m.) and free access to regular lab chow and tap water. During the experiment, body weight gain was monitored to enable volume calculation of $\mathrm{As}_{2} \mathrm{O}_{3}$ to be administered.

Animals were randomly allocated into three experimental groups $(n=10)$ : control received distilled water (vehicle) while treated groups received 0.3 or $3 \mathrm{mg} / \mathrm{kg} /$ day of $\mathrm{As}_{2} \mathrm{O}_{3}$ (Acros 1327-53-3, Arsenic (III) Oxide, 99.5\%), subcutaneously (sc), for 5 days per week, followed by 2 days of interruption, for 5 weeks. At the end of treatment, animals were weighed and euthanized by cervical dislocation to assess treatment-related effects on male reproductive organs. The doses used in this study were based upon chemotherapy concentrations utilized for humans, wherein the effective dose for the treatment of APL varies from 0.06 to $0.2 \mathrm{mg} / \mathrm{kg}$; above this dose, there is no difference in efficacy (Soignet et al. 1998). The highest dose of $3 \mathrm{mg} / \mathrm{kg}$ corresponds to the dose of $0.2 \mathrm{mg} / \mathrm{kg}$ in humans, based on the normalization for body surface area proposed by (Reagan-Shaw, Nihal, and Ahmad 2008).

\section{Sperm morphology}

Sperm were removed from the left vas deferens by internal rinsing with $0.5 \mathrm{ml}$ formol-saline solution. Smears were prepared on histological slides that were left to dry for $90 \mathrm{~min}$ and observed with a 
phase-contrast microscope (400× magnification) (Seed et al. 1996). Two hundred spermatozoa were analyzed per animal, and morphological abnormalities were classified into two general categories: head morphology and tail. Sperm were also classified as to the presence or absence of cytoplasmic droplet (Filler, 1993).

\section{Histopathological evaluation}

The left testis and epididymis were collected and fixed in Bouin's fluid for $24 \mathrm{~h}$ (25\% formaldehyde, $70 \%$ saturated solution of picric acid, and 5\% glacial acetic acid). The pieces were embedded in paraffin wax and sectioned at $5 \mu \mathrm{m}$ (cross sections of the testis). Sections used for histopathological and stereological evaluation were stained with hematoxylin and eosin (HE), examined and photographed by light microscopy. The assessments were performed in blind assays and photomicrographs for documentation were captured by a digital camera coupled to the Nikon Eclipse E-400 light microscope (Nikon, Tokyo, Japan). Seminiferous tubule cross sections were randomly selected in three non-serial sections per animal, totaling 100 tubules per animal. These were classified as normal (presence of concentric and normally organized germ cell layers in seminiferous epithelium) or abnormal (presence of germ cells and cellular debris in the lumen, multinucleated formation, few germ cell layers, vacuole formation).

\section{Evaluation of the spermatogenic process}

In the seminiferous tubules, 100 cross sections per animal were analyzed (those which displayed more regular and circular form possible in stage I to XII) and characterized as follows:

Stages I to III: two generations of spermatids;

Stages IV to VI: mature spermatozoa located in the lumen border;

Stages VII to IX: only one generation of spermatids; Stages $X$ to XII: presents secondary spermatocyte.

\section{Testis stereological analysis}

Ten photomicrographs randomly obtained on the Image Pro Plus software associated with a Nikon Eclipse E-400 light microscope (Nikon, Tokyo,
Japan) with $400 \times$ magnification were employed. A grid with 432 intersections was placed over the photomicrographs and the proportion of tubular epithelium, tubular lumen and interstitium was obtained based on total of intersections according to the method modified by de Souza Predes, Diamante, and Dolder (2010). Taking into consideration the density of this organ as 1 , testis weight was considered the same as its volume (França and Russel 1998). Thus, these results were used to calculate the volume of testicular components.

To evaluate the interstitial components (lymphatic space, blood vessels, macrophages, and Leydig cells), 2000 intersections were counted on photomicrographs randomly obtained with $400 \times$ magnification. A grid with 432 intersections was placed over the photomicrograph and the proportion of each component was obtained based on the total of intersections according to the method modified by de Souza Predes, Diamante, and Dolder (2010). To calculate their volume, the total volume of testis was used (França and Russel 1998).

The individual Leydig cell volume was determined counting 500 intersections on random photomicrographs with $1000 \times$ magnification. A grid with 432 intersections was placed over the photomicrographs and 10 nuclei diameters per animal were measured modified from Leite et al. (2013). The nuclear and cytoplasmic proportions were calculated based on the total of intersections. According to these results and with the following formulas, the nuclear and cytoplasmic volume was calculated: nuclear volume $=4 / 3 \pi R^{3}$, considering $R=$ nuclear radius and the cytoplasmic volume $=(\%$ cytoplasm $\times$ nuclear volume $) / \%$ nucleus. The sum of those volumes enables calculating the individual Leydig cell volume. To calculate the number of Leydig cells per testis, the total Leydig cell volume was divided by individual Leydig cell volume. The number of Leydig cells/g testis was calculated dividing the number of Leydig cells per testis by the respective parenchyma weight.

\section{Immunohistochemical analysis}

The testes and epididymis collected from animals in control and $3 \mathrm{mg} / \mathrm{kg}$ groups were also used for 
immunohistochemical analyses. Antigens were retrieved by boiling the sections in $10 \mathrm{mM}$ citrate buffer, pH 6 in a microwave oven. Subsequently, sections were incubated in $0.3 \% \mathrm{H}_{2} \mathrm{O}_{2}$ for $20 \mathrm{~min}$ to block endogenous peroxidase and nonspecific binding was inhibited by incubating the sections in a blocking solution (BSA 1\%) for $1 \mathrm{~h}$ at room temperature. Primary rabbit polyclonal anti-AR (sc-816) (Santa Cruz Biotechnology, California, USA) for AR were diluted in $1 \%$ bovine serum albumin (BSA) (1:50) and applied to the sections overnight at $4^{\circ} \mathrm{C}$. Samples that were not incubated with primary antibody were used as negative controls. The sections were incubated for $2 \mathrm{~h}$ with rabbit secondary horseradish peroxidase -conjugated antibodies (Promega, Madison, diluted $1: 100$ in $1 \%$ BSA). Harris' hematoxylin was used for counterstaining. In the testis, positive AR was found in different cell types including Sertoli cells, Leydig cells, and cells surrounding seminiferous tubule (peritubular cells) such that immunoreactivity for these cells were counted separately and expressed as mean value per $\mu \mathrm{m}^{2}$ obtained from the 15 fields in each animal, totaling 75 fields per group. The epididymal sections of each group were determined using a multipoint system with 160 intersections (Weibel 1963). For this analysis, 10 fields of head and 10 fields of cauda epididymis were captured randomly per animal, totaling 100 fields per group. Values were determined by immunoreactivity counting coinciding with the grid intersection divided by total number of points. Results were expressed as a relative frequency of positive staining for AR in all experimental groups.

\section{Fertility test}

At the end of treatment, animals from control and treated groups $(n=10)$ were mated with female mice (60 days of age) to assess the effects of the drug on male fertility capacity. For this, each male was paired with two females for the night and, the next morning females were evaluated for the presence of vaginal plug, which was determined as gestational day (GD) 0 . The weight of females was recorded on GD $0,6,12$, and 18. On GD 18, females were euthanized by cervical dislocation for assessment of following parameters: fertility potential as evidenced by number of implants/corpora lutea $\times 100$ and fetal viability as evidenced by number of live fetus/implants $\times 100$. At the birth, the fetus and placenta weight were recorded.

\section{Statistical analysis}

Data are presented as mean \pm standard error of mean (SEM). Parametric variables were compared by analysis of variance (ANOVA) followed by the test of Dunnet or Dunn's. Differences were considered significant when $p<.05$. Statistical analyses were performed by the software GraphPad Prism (version 5.0).

\section{Results}

\section{Effect on sperm morphology and germ epithelium degeneration}

The $3 \mathrm{mg} / \mathrm{kg} \quad \mathrm{As}_{2} \mathrm{O}_{3}$-treated animals produced a significant reduction in \% normal sperm (Figure 1A); although the lower dose $(0.3 \mathrm{mg} / \mathrm{kg})$ initiated a numerical non-significant lower number of normal sperm. Further, the most frequent abnormality observed was the presence of isolated sperm heads (i.e., without tail) in the tissue samples from animals that received the drug (Figure 1B). There was no significant difference in the presence of cytoplasmic droplet in sperm tail (Figure 1C).

Testicular histopathology demonstrated a significant decrease in normal seminiferous tubule number in both $\mathrm{As}_{2} \mathrm{O}_{3}$-treated groups (Figures $2 \mathrm{~A}$ and 3). In these animals, the most frequent abnormalities found were increase of seminiferous epithelium degeneration and germ cell exfoliation of tubular lumen. Spermatogenic process analysis displayed no marked differences among the proportions of tubules in certain stages in experimental groups (Figure 2B).

\section{Effect on Leydig cells}

Interstitial cell component evaluation demonstrated a reduction in volumetric proportion and Leydig cells volume in the group treated with $3 \mathrm{mg} / \mathrm{kg} \quad \mathrm{As}_{2} \mathrm{O}_{3}$. In addition, there was a significant increase in volumetric proportion of lymphatic space (54\%) in this same group 
A

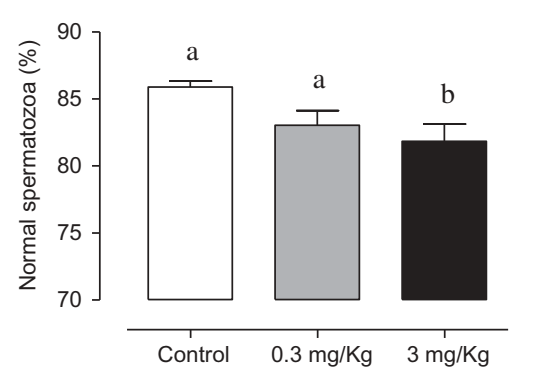

C
B

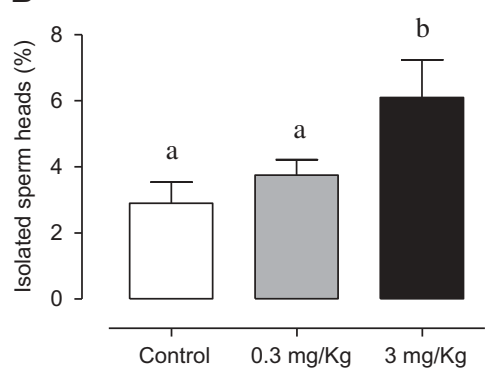

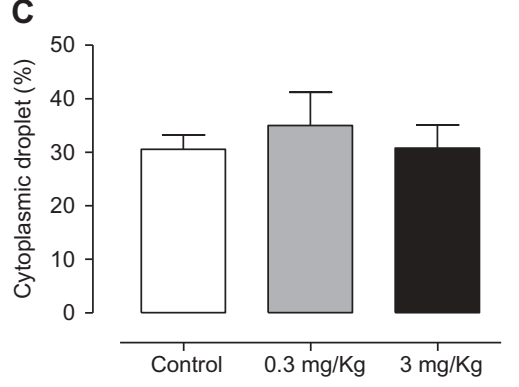

Figure 1. Sperm morphology. (A) Percentage of normal spermatozoa, (B) of isolated head (i.e., without tail), and (C) cytoplasmic droplet presence in the control and $\mathrm{As}_{2} \mathrm{O}_{3}$-treated groups $(n=10)$. Values expressed as percentage. One-way analysis of variance (ANOVA) test, followed by Dunn's test.

*Significant from control $p<.05$.

compared to control (45\%) (Figure 2C). No marked differences were observed in macrophages and blood vessels volume (data not shown). Although an alteration in lymphatic space and Leydig cells volume was noted in $0.3 \mathrm{mg} / \mathrm{kg}$ group, the results were not significantly different from control. There was no marked difference in volume of seminiferous tubules, interstitial space, epithelium, and tubular lumen between experimental groups (Figure 2D). Further, there were no marked alterations in testicular volumetric proportion of these components (data not shown). Finally, there were no significant differences in volumetric proportion and macrophage volume and blood vessels following all treatments. The highest concentration $3 \mathrm{mg} / \mathrm{kg} \quad \mathrm{As}_{2} \mathrm{O}_{3}$ significantly elevated nuclear region of Leydig cells accompanied by a decrease in cytoplasmic region. Regarding the nuclear diameter, total volume of a Leydig cell, number of Leydig cells per testis or per gram of testis, no marked differences were detected between all experimental groups (Table 1).

Testis from $3 \mathrm{mg} / \mathrm{kg} \mathrm{As} \mathrm{O}_{3}$ treated animals displayed significant decreased AR immunostaining in Leydig cells (Figures 4A and 5) accompanied by a numeric reduction in immunoreactivity in Sertoli and peritubular cells (Figures 4B, 4C, and 5), as well as in epididymal epithelial cells (Figures $4 \mathrm{D}$ and 5), both in the caput/corpus and cauda of this organ.

\section{Influence on fertile capacity}

When $3 \mathrm{mg} / \mathrm{kg} \quad \mathrm{As}_{2} \mathrm{O}_{3}$-treated male mice were mated with non-exposed females, a significant fall in fetal viability was noted as evidenced by a rise in fetus mortality rate after implantation (Figure 6A). No marked changes were observed on fertility potential or body weight gain of pregnant females (Figure 6A and 6B).

\section{Discussion}

Soignet et al. (1998) reported that $\mathrm{As}_{2} \mathrm{O}_{3}$ is capable of inducing complete remission in APL patients, since this drug produces cytodifferentiation of leukemic cells, followed by caspases activation and apoptosis induction. A portion of this efficiency may be attributed to release of a mitochondrial apoptosis-inducing factor that is translocated to the cell nucleus, altering chromatin condensation 
A
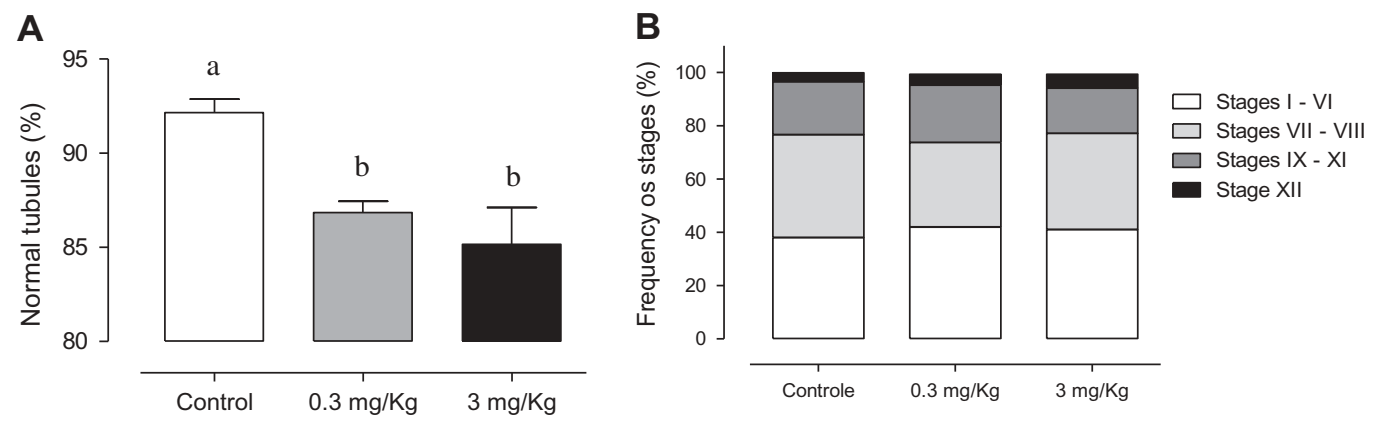

C
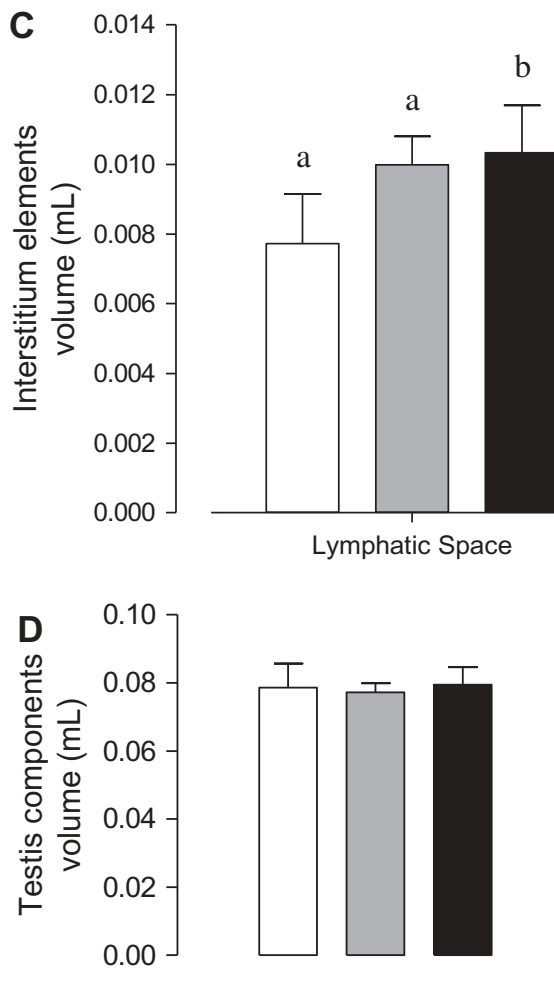

Epithelium

Figure 2. Histopathological and stereological evaluation of testis. (A) Normal tubule frequency, (B) evaluation of the spermatogenic process, (C) interstitium elements volume, and (D) testicular components volume in the control and $\mathrm{As}_{2} \mathrm{O}_{3}$-treated groups. Values expressed as percentage in (A) and (B) (ANOVA followed by Dunnett test), and expressed as mean \pm SD in (C) and (D) (ANOVA followed by Dunnett test).

*Significant from control $p<.05$.

with consequent DNA breakage (Lorenzo et al. 1999; Susin et al. 1999). In addition to DNA damage, As inactivates approximately 200 enzymes related to replication/repair cell system (Bernstam and Nriagu 2000; Ratnaike 2003). Despite the therapeutic benefits of $\mathrm{As}_{2} \mathrm{O}_{3}$, there are numerous studies indicating the As exposure produces disturbances including hepatitis, hyperpigmentation, keratosis, ocular defects, leukocytosis, and neuropathies, in addition to reproductive system damage such as spermatotoxicity, inhibition of testicular androgenesis and testes and accessory organs reduced weight ( $\mathrm{Au}$ et al., 2003; Bernstam and Nriagu 2000; Kleiman et al. 2016; Mazumder et al. 1998; Pant, Murthy, and Srivastava 2004; Sarkar et al. 2003; Shen et al. 1997; Souza et al. 2016).

Among other pathways not completely clear in $\mathrm{As}_{2} \mathrm{O}_{3}$ therapeutic use of APL is the role of ROS generation, which produces cell cycle arrest and apoptosis in several cell types, leading to pro- and anti-apoptotic imbalance (Liu et al. 2015). Generation of ROS occurs normally and it is considered necessary for cell physiology, including 


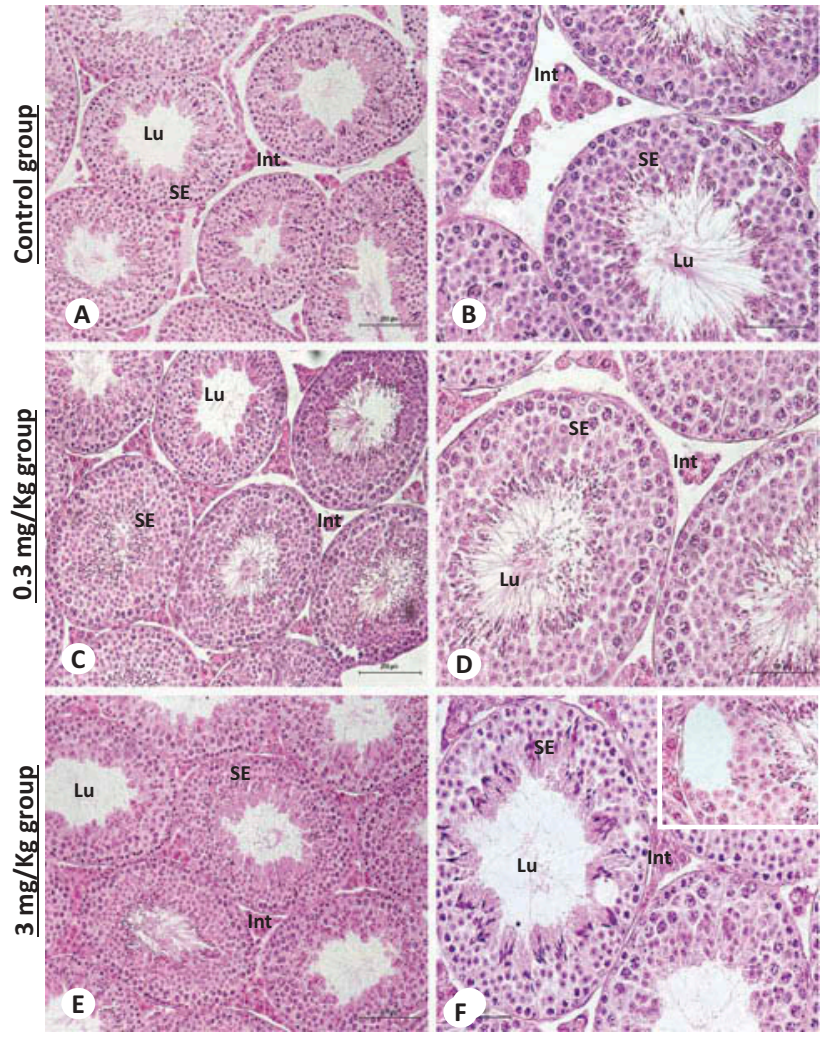

Figure 3. Photomicrograph of the testis from different experimental groups. (A, B) Control group (A, 200× e B, 400X); (C, D) treated with $0.3 \mathrm{mg} / \mathrm{kg}(C, 200 \times$ e $D, 400 \times) ;(E, F) 3 \mathrm{mg} / \mathrm{kg}\left(E_{\text {, }}\right.$ 200x e $F, 400 \times$ ) of $\mathrm{As}_{2} \mathrm{O}_{3}$. SE = seminiferous epithelium; $\mathrm{Lu}=$ lumen; Int = interstitium; $\mathrm{Va}=$ vacuole.

mediation of spermatozoa normal function. However, uncontrolled or excessive production disturbs normal redox state of the cell, leading to damage of cellular components such as proteins, DNA, and lipids, resulting in several pathological processes in reproductive system of exposed individuals as evidenced by decreased sperm concentration and abnormal sperm formation ( $\mathrm{Li}$ et al. 2015; Sharma and Agarwal 1996). The abnormalities found in spermatozoa affect the fertilization process since these alterations present high quantities of DNA damage, leading to infertility ( $\mathrm{He}$ and Tan 2015). Therefore, $\mathrm{As}_{2} \mathrm{O}_{3}$ exposure has been attributed to result in malformations both in spermatozoa as detected in seminiferous tubule components as well as increased DNA damage in spermatogenic cells (Mukhopadhyay et al. 2013). Recently, Li et al. (2016) showed that $5 \mathrm{mg} / \mathrm{kg} /$ day $\mathrm{As}_{2} \mathrm{O}_{3}$ treatment of mice for 35 days reduced normal sperm number. In agreement with these findings Xia, Hao, and Yang (2009) noted that these effects also occurred in rats treated with 4 or $8 \mathrm{mg} /$ $\mathrm{kg}$ /day as the rate of malformed sperm was elevated. In the present study, low $\mathrm{As}_{2} \mathrm{O}_{3}$ dose administration also produced damage in mice sperm. Although humans receive treatment intravenously, the chosen route for drug administration herein was subcutaneous since when anticancer drugs are given subcutaneously they display higher bioavailability $(+80 \%)$ compared to the other routes, also being rapidly absorbed. Besides, the drug delivery by this route does not have impact on the elimination rate when compared to the intravenous route (Leveque 2014).

Although a recent case study showed that six patients successfully treated with $\mathrm{As}_{2} \mathrm{O}_{3}$ parented healthy child (Gupta et al. 2012), several studies demonstrated the harmful effects of heavy metals such as As, cadmium (Cd), and nickel (Ni) on male reproductive function due to their ability to enhance production of ROS and subsequent DNA damage as evidenced by altered testicular ultrastructure, depletion/degradation of seminiferous tubules, and alterations in interstitial components (da Silva et al. 2016; de Souza Predes, Diamante, and Dolder 2010; Lamas, Gollucke, and Dolder 2015; Li et al. 2015; Morales et al. 2016;

Table 1. Leydig cell stereology.

\begin{tabular}{lcccc}
\hline Parameters & & Control & $0.3 \mathrm{mg} / \mathrm{kg}$ & $3 \mathrm{mg} / \mathrm{kg}$ \\
\hline Nuclear diameter & $(\mu \mathrm{m})$ & $16.68 \pm 0.4$ & $16.70 \pm 0.2$ & $16.97 \pm 0.4$ \\
Nucleus & $(\%)$ & $24.25 \pm 1.1$ & $29.48 \pm 1.5^{*}$ & $32.84 \pm 0.9^{*}$ \\
& $\left(\mu \mathrm{m}^{3}\right)$ & $2242 \pm 4.4^{+2}$ & $2577 \pm 78.6^{+2}$ & $2878 \pm 1.8^{+3^{*}}$ \\
Cytoplasm & $(\%)$ & $75.75 \pm 1.1$ & $70.52 \pm 1.5^{*}$ & $67.16 \pm 0.9^{*}$ \\
& $\left(\mu \mathrm{m}^{3}\right)$ & $7775 \pm 1.0^{+3}$ & $5952 \pm 5.6^{+2^{*}}$ & $5266 \pm 3.6^{+2^{*}}$ \\
Total volume of a Leydig cell & $\left(\mu \mathrm{m}^{3}\right)$ & $9037 \pm 4.7^{+2}$ & $9106 \pm 7.8^{+2}$ & $7845 \pm 5.5^{+2}$ \\
Number Leydig/testis & $\left(\times 10^{7}\right)$ & $1.95^{+6} \pm 1.5^{+5}$ & $1.98^{+6} \pm 2.0^{+5}$ & $2.43^{+6} \pm 2.0^{+5}$ \\
Number Leydig/g Testis & $\left(\times 10^{7}\right)$ & $1.68^{+7} \pm 6.5^{+5}$ & $1.67^{+7} \pm 2.2^{+6}$ & $2.31^{+7} \pm 2.2^{+6}$ \\
\hline
\end{tabular}

Values expressed as mean + SEM. One-way analysis of variance (ANOVA) test, followed by Dunnet test.

*Significant from control $p<.05$. 

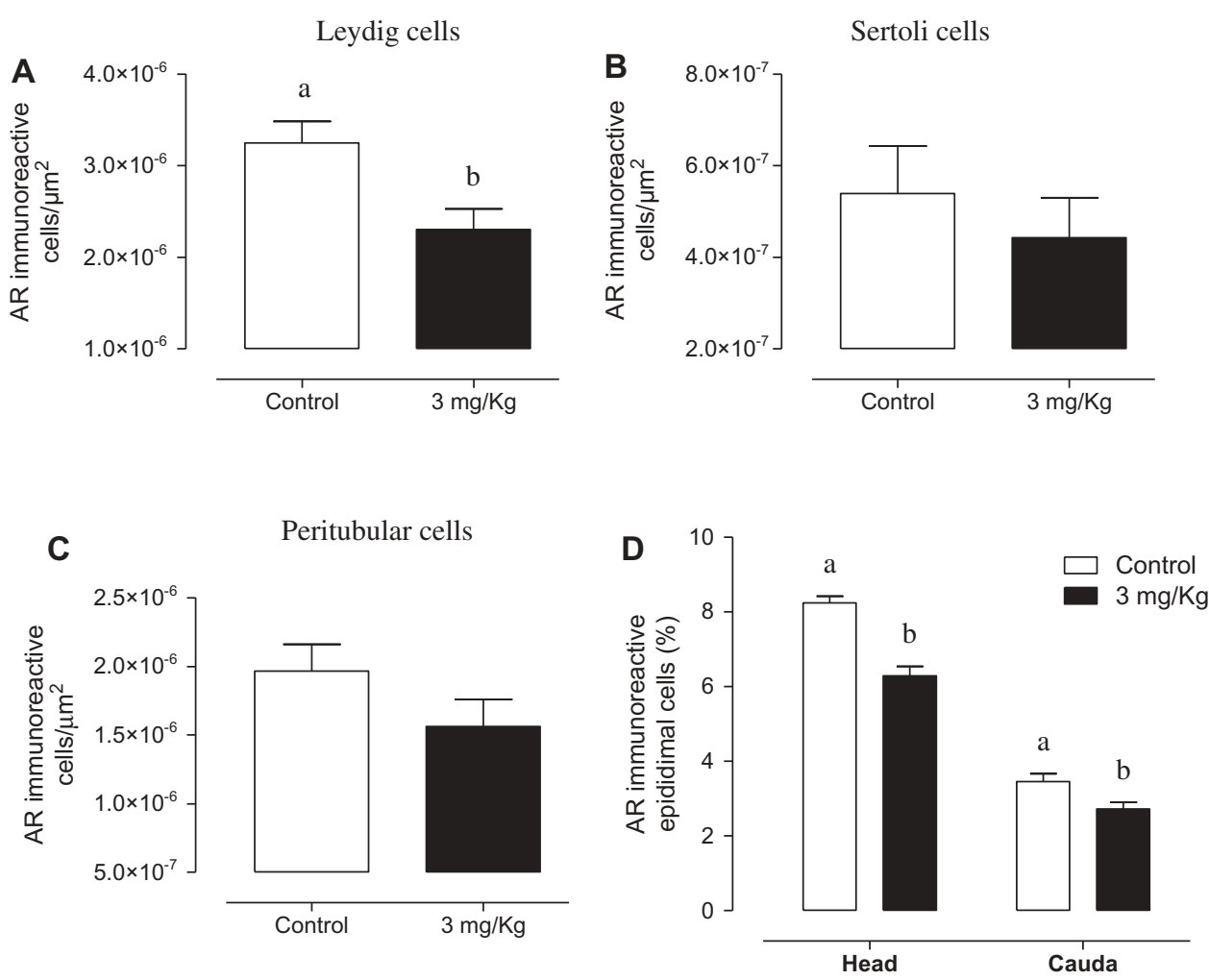

Figure 4. A: Sertoli, B: Peritubular and C: Leydig cells in the control group and treated group. D: AR immunoreactivity in head and cauda epididymis. Two-tailed Student's t-test.

*Significant from control $p<0.05$.

Mukhopadhyay et al. 2013; Pandey et al. 1999). Several mechanisms have been described for adverse effects of toxic chemicals on reproductive system. First, $\mathrm{As}_{2} \mathrm{O}_{3}$ metabolites accumulate mainly in liver, kidneys, and blood and elevated ROS production generates systemic toxicity, affecting the testis (Thomas, Styblo, and Lin 2001). Secondly, chemicals also may affect the hypothalamic-pituitary and change $\mathrm{LH}$ and FSH plasma concentrations, resulting in an impairment of Leydig cell function and decreased testosterone production; and finally, the toxic chemical might exert an inhibitory action directly on testis (Kim and Kim 2015).

These substances might reach the immune-privileged environment provided by the blood-testis barrier (BTB) and resultant oxidative stress might damage the Sertoli supporting cells by disrupting the inter-Sertoli tight junctions. The disruption on these cells may increase BTB permeability, leading to changes in Leydig cells and decreased testosterone levels (Marettova, Maretta, and Legath 2015; Stanton 2016). Guvvala, Sellappan, and
Parameswaraiah (2016) showed that As accumulation in the testes is responsible for damage in the testicular architecture, and that the metal gained access to testicular compartment by crossing the BTB.

One of these alterations is increased volumetric proportion of lymphatic space in the testis, probably due to lymphatic vessel proliferation. The lymphatic system is organized as lymphatic sinusoids around the seminiferous tubules that occupy the interstitial periphery. Leydig cells are found surrounding these lymphatic vessels and testosterone exits the testis through these lymphatic vessels in addition to blood vessels (Fawcett, Neaves, and Flores 1973). The lymphatic space increase found after exposure to the higher dose of $\mathrm{As}_{2} \mathrm{O}_{3}$ may be related to the capacity of these vessels to scavenge toxic substances to maintain testicular homeostasis following intoxication. Another explanation for this alteration might be associated with endoplasmic reticulum (ER) stress, which is noted when there is elevated protein folding demand that exceeds the ER capacity, leading to an 
Testis
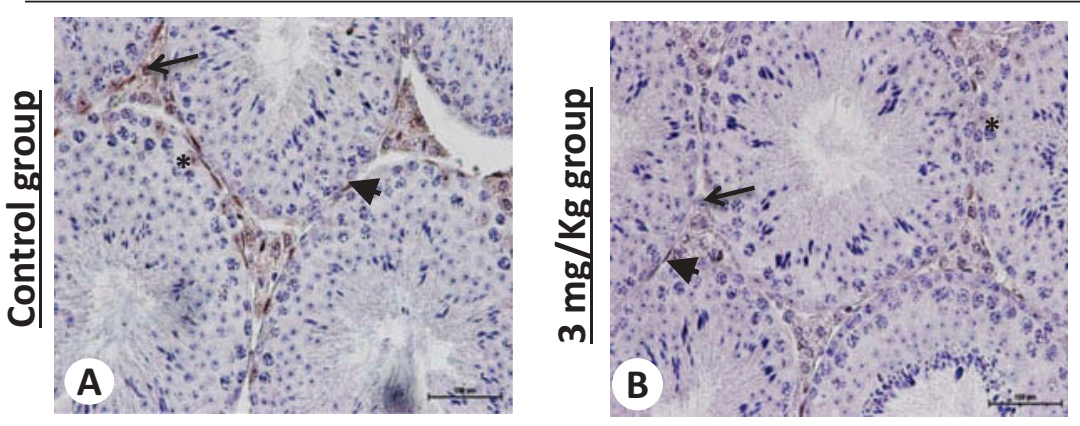

Epidydimis

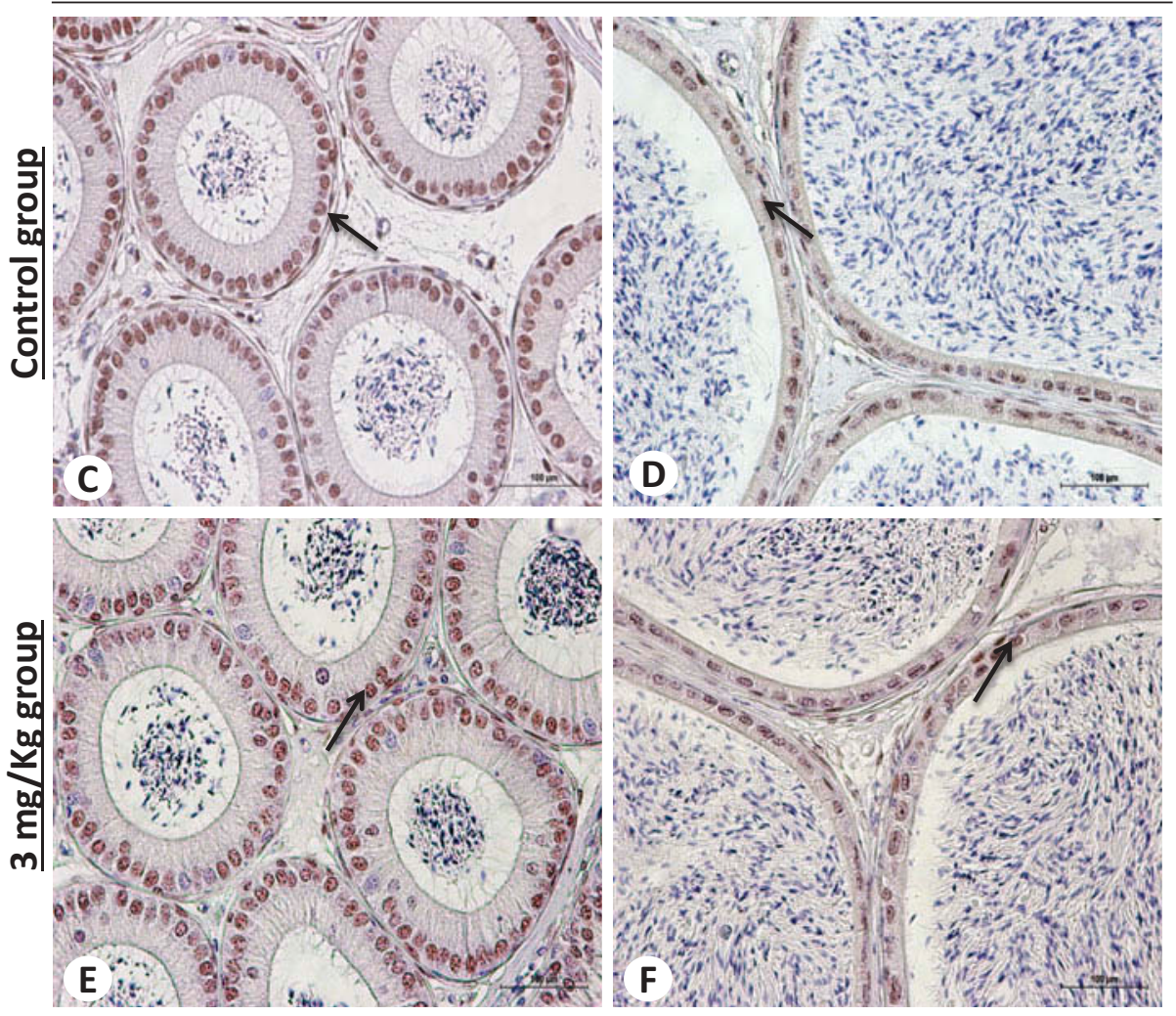

Figure 5. Androgen receptor (AR) immunolabeling. (A) Testis in the control group and (B) $\mathrm{As}_{2} \mathrm{O}_{3}$-treated group; positive AR markers are indicated by arrows in Leydig cells, arrow heads in peritubular cells and asterisks in Sertoli cells. Epididymis from control group (C, D) and treated (E, F) groups; positive markers for AR in epididymis epithelium are indicated by arrows. Counterstain: Harris hematoxylin, 400x.

accumulation of these proteins within the ER. Foufelle and Fromenty (2016) proposed that ER stress was related to toxic action of some drugs such as $\mathrm{As}_{2} \mathrm{O}_{3}$ since ROS accumulation occurred due to metallic exposure resulting in impaired protein folding and subsequent deleterious effects including inflammation. During inflammatory processes, changes such as increased lymphatic vessel proliferation rate occur in the lymphatic system in order to deliver immune cells to the damaged tissue to be regenerated, which may account for the elevated lymphatic space after $\mathrm{As}_{2} \mathrm{O}_{3}$ exposure (Granger and Senchenkova 2010).

Trivalent form of As produced adverse effects as evidenced by rise in abnormalities in seminiferous tubules histoarchitecture characterized by germinative epithelial degeneration and germ cell exfoliation in tubular lumen. These alterations might be associated with lower levels of serum testosterone, which may lead germ cells 

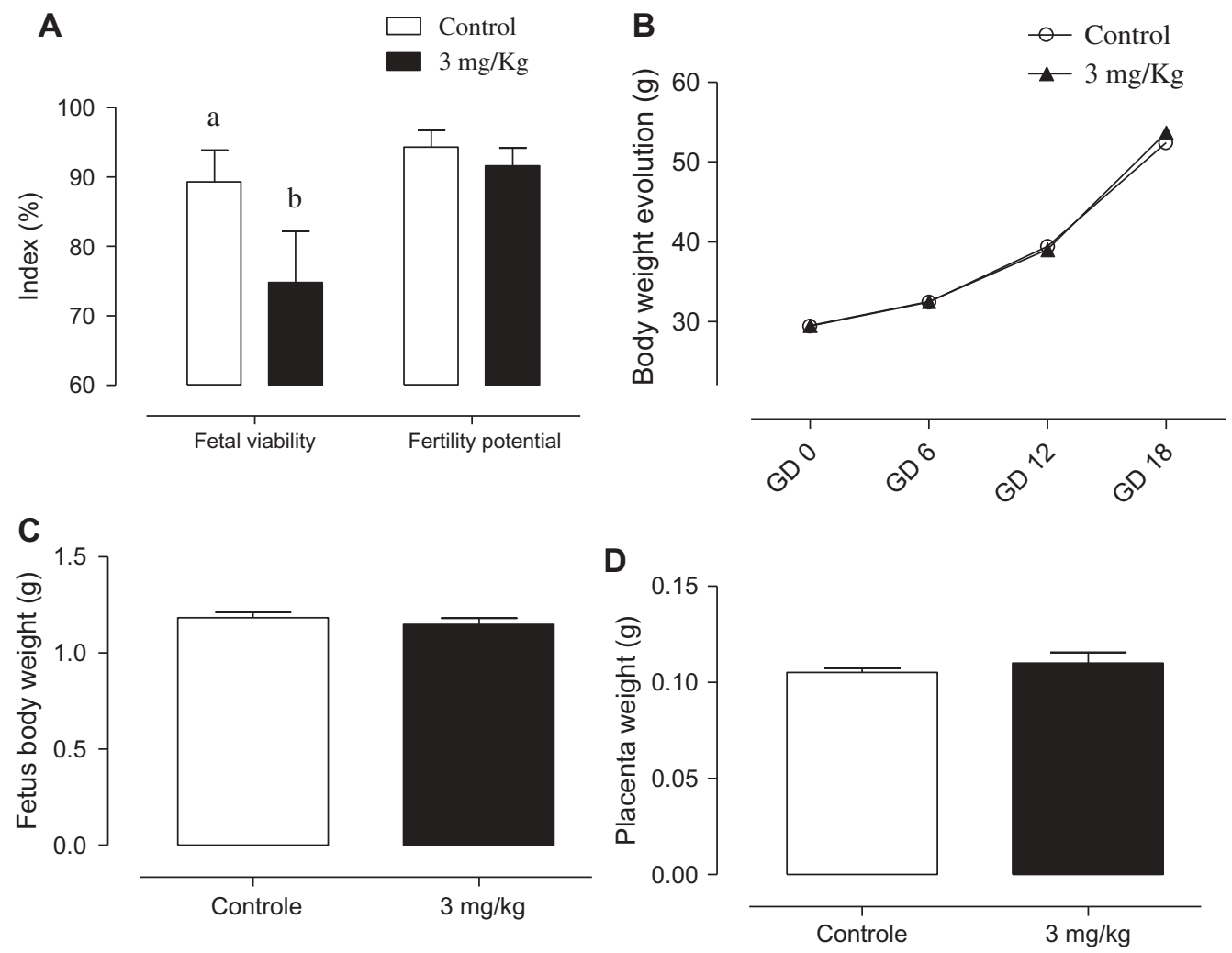

Figure 6. Fetal viability, fertility potential and body weight gain. A: Indexes of fetal viability and fertility potential of females mated with control and $\mathrm{A}_{\mathrm{s} 2} \mathrm{O}_{3}$ treated male mice. Values expressed as percentage, chi-square test, $n=10$. B: Body weight gain of pregnant females. C: Fetus body weight on GD18. D: Placenta weight on GD18. For B, C and D, values were expressed as mean \pm S.E. M. Two-tailed Student's t-test. GD: gestational day.

to detach from epithelium, as this hormone plays an important role in enabling germ cells to remain attached to the lumen (BlancoRodriguez and Martinez-Garcia 1997; Mohammad et al. 2013). Previously da Silva et al. (2016) showed that in animals exposed to $\mathrm{As}_{2} \mathrm{O}_{3}$ reduced serum testosterone levels were found, even after termination of treatment, indicating that this alteration on steroidogenesis may be persistent and impairs reproductive functions of male mice. In agreement with these findings, Chiou et al. (2008) reported that $\mathrm{As}_{2} \mathrm{O}_{3}$ exposure reduced gene expression of key enzymes involved in testosterone synthesis. The altered serum testosterone levels produced by $\mathrm{As}_{2} \mathrm{O}_{3}$ exposure might be related to changes in reduced volume of Leydig cells and diminished volumetric proportion of interstitium space noted in this study.

In mammalians, $A R$ is mainly found in Sertoli cells; however, this receptor may also be found in Leydig cells and peritubular cells. The activation of
$\mathrm{AR}$ is attributed to testosterone and dihydrotestosterone binding, leading to activation of target genes, which is fundamental to successful spermatogenesis. Interference by chemical exposure of AR binding leads to infertility (Chojnacka et al. 2012). Rosenblatt and Burnstein (2009) reported that Asinduced toxicity in male reproductive system might be associated with inhibition of AR activity since metallic exposure was able to block transcriptional activity of this receptor. In this study, significant decreased AR immunoreactivity in Leydig and epididymal epithelial cells may be related to $\mathrm{As}_{2} \mathrm{O}_{3}$ interference with the cysteine residues present in DNA-binding domain of AR (Rosenblatt and Burnstein 2009), since AR staining was significantly less frequent in the $3 \mathrm{mg} / \mathrm{kg}$ dose group. The AR expression in Leydig cells regulates hormonal production, and lack of a functional AR expression interferes with steroidogenesis, inducing spermatogenic cycle arrest and increasing the number of sperm abnormalities (Abd El-Meseeh et al. 2016; Tsai et al. 2006). Taken together, these findings 
corroborate the abnormal sperm morphology found herein and in a study previously published by da Silva et al. (2016) where mice given $\mathrm{As}_{2} \mathrm{O}_{3}$ showed reduced testosterone levels.

In toxicological studies, assessment of seminiferous tubule staging is important as a bioindicator of defects in spermatogenic process since it is possible to identify which cell type are affected by chemical exposure (Meistrich and Hess 2013). However, administration of low dose $\mathrm{As}_{2} \mathrm{O}_{3}$ did not disrupt seminiferous tubule staging in the present study.

Since $\mathrm{As}_{2} \mathrm{O}_{3}$ is widely used for treatment of APL, it is important to evaluate the chemotherapeutic side effects. Administration of $\mathrm{As}_{2} \mathrm{O}_{3}$ impaired fertility both in men and women and thus concern arose that patients treated with this drug may adversely affect reproductive performance in childbearing years (Stein and Tallman 2012). Genomic alterations such as sperm DNA damage induced by $\mathrm{As}_{2} \mathrm{O}_{3}$-related oxidative stress may compromise fertilization, embryo viability, and intrauterine development, making pregnancy not feasible to progress due to consequent postfertilization detrimental effects (Borini et al. 2006; Dimitriadis et al. 2009). It is noteworthy that reduced fetal viability in non-exposed females mated with high-dose $\mathrm{As}_{2} \mathrm{O}_{3}$-treated males demonstrated that exposure to this drug also elevated post-implantation loss.

\section{Limitations}

Although our study showed harmful effects of $\mathrm{As}_{2} \mathrm{O}_{3}$ on male reproductive system, the results are not sufficient to discard its efficient use in APL chemotherapy since further studies are required to demonstrate the influence of this metallic drug in pregnancy outcome and birth defects.

\section{Conclusions}

Our study indicated that exposure to $\mathrm{As}_{2} \mathrm{O}_{3}$ impaired reproductive function in adult male mice associated with oxidative damage. Effects noted were concomitant adverse alterations in germ epithelium and steroid hormone receptors as well as post-implantation loss observed in females mated with drug-treated males. All these changes on sperm parameters led to altered sperm quality and lower fetal viability. These findings indicate that patients treated with $\mathrm{As}_{2} \mathrm{O}_{3}$ may be at risk if individuals are contemplating having children in the future.

\section{Acknowledgments}

The authors are grateful to $\mathrm{CNPq}$, The São Paulo Research Foundation (FAPESP 2012/14342-8) and the Coordinator for Improvement of Higher Education Personnel (CAPES), for graduate scholarships and to José Eduardo Bozano, from the Department of Morphology of UNESP, for the excellent technical assistance. Dr. Wilma De Grava Kempinas is recipient of a senior research fellowship from CNPq (National Council for Scientific and Technological Development).

\section{Funding}

This work was supported by The São Paulo Research Foundation; [FAPESP 2012/14342-8]; Improvement of Higher Education Personnel (CAPES).

\section{Conflict of interest statement}

The authors declare that there are no conflicts of interest.

\section{References}

Abd El-Meseeh, N. A., E. A. El-Shaarawy, A. F. AlDomairy, and R. A. Sehly. 2016. Changes in rat testis morphology and androgen receptor expression around the age of puberty. Annals of Anatomy - Anatomischer Anzeiger 205:3744. doi:10.1016/j.aanat.2016.01.003.

Au, W. Y., C. R. Kumana, M. Kou, R. Mak, G. C. Chan, C. W. Lam, and Y. L. Kwong. 2003. Oral arsenic trioxide in the treatment of relapsed acute promyelocytic leukemia. Blood 102:407-408. doi:10.1182/blood-2003-01-0298.

Bernstam, L., and J. Nriagu. 2000. Molecular aspects of arsenic stress. Journal of Toxicology and Environmental Health, Part B 3:293-322. doi:10.1080/109374000436355.

Blanco-Rodriguez, J., and C. Martinez-Garcia. 1997. Apoptosis pattern elicited by oestradiol treatment of the seminiferous epithelium of the adult rat. Journal of Reproduction and Fertility 110:61-70. doi:10.1530/ jrf.0.1100061.

Borini, A., N. Tarozzi, D. Bizzaro, M. A. Bonu, L. Fava, C. Flamigni, and G. Coticchio. 2006. Sperm DNA fragmentation: Paternal effect on early post-implantation embryo development in ART. Human Reproduction 21:28762881. doi:10.1093/humrep/del251.

Chen, G. Q., X. G. Shi, W. Tang, S. M. Xiong, J. Zhu, X. Cai, Z. G. Han, J. H. Ni, G. Y. Shi, P. M. Jia, M. M. Liu, K. L. 
He, C. Niu, J. Ma, P. Zhang, T. D. Zhang, P. Paul, T. Naoe, K. Kitamura, W. Miller, S. Waxman, Z. Y. Wang, H. de The, S. J. Chen, and Z. Chen. 1997. Use of arsenic trioxide (As2O3) in the treatment of acute promyelocytic leukemia (APL): I. As2O3 exerts dose-dependent dual effects on APL cells. Blood 89:3345-3353.

Chiou, T. J., S. T. Chu, W. F. Tzeng, Y. C. Huang, and C. J. Liao. 2008. Arsenic trioxide impairs spermatogenesis via reducing gene expression levels in testosterone synthesis pathway. Chemical Research in Toxicology 21:1562-1569. doi:10.1021/tx700366x.

Chojnacka, K., R. Brehm, K. Weider, A. Hejmej, M. Lydka, I. Kopera-Sobota, and B. Bilinska. 2012. Expression of the androgen receptor in the testis of mice with a Sertoli cell specific knock-out of the connexin 43 gene (SCCx43KO -/-). Reproductive Biology 12:341-346. doi:10.1016/j. repbio.2012.10.007.

Cicconi, L., and F. Lo-Coco. 2016. Current management of newly diagnosed acute promyelocytic leukemia. Annals of Oncology 27:1474-1481. doi:10.1093/annonc/mdw171.

da Silva, R. F., S. Borges Cdos, E. Silva, P. Villela, G. Missassi, L. R. Kiguti, A. S. Pupo, F. Barbosa, Junior, J. A. AnselmoFranci, and W. D. G. Kempinas. 2016. The coadministration of $\mathrm{N}$-acetylcysteine ameliorates the effects of arsenic trioxide on the male mouse genital system. Oxidative Medicine and Cellular Longevity 2016:1-11. doi:10.1155/ 2016/4257498.

De Souza Predes, F., M. A. Diamante, and H. Dolder. 2010. Testis response to low doses of cadmium in Wistar rats. International Journal of Experimental Pathology 91:125131. doi:10.1111/iep.2010.91.issue-2.

Dimitriadis, F., D. Giannakis, N. Pardalidis, K. Tsoukanelis, N. Kanakas, M. Saito, T. Watanabe, I. Miyagawa, P. Tsounapi, and N. Sofikitis. 2009. Effects of primary testicular damage on sperm DNA oxidative status and embryonic and foetal development. Andrologia 41:282-296. doi:10.1111/and.2009.41.issue-5.

Emadi, A., and S. D. Gore. 2010. Arsenic trioxide - An old drug rediscovered. Blood Reviews 24:191-199. doi:10.1016/ j.blre.2010.04.001.

Fan, X. Y., X. Y. Chen, Y. J. Liu, H. M. Zhong, F. L. Jiang, and Y. Liu. 2016. Oxidative stress-mediated intrinsic apoptosis in human promyelocytic leukemia HL-60 cells induced by organic arsenicals. Scientific Reports 6:29865. doi:10.1038/ srep29865.

Fawcett, D. W., W. B. Neaves, and M. N. Flores. 1973. Comparative observations on intertubular lymphatics and the organization of the interstitial tissue of the mammalian testis. Biology of Reproduction 9:500-532. doi:10.1093/biol$\mathrm{reprod} / 9.5 .500$.

Filler, R. 1993. Methods for evaluation of rats epididymal sperm morphology. In Male reproductive toxicology, ed. C. R. H. JH, 334-343. San Diego, California: Academic Press.

Foufelle, F., and B. Fromenty. 2016. Role of endoplasmic reticulum stress in drug-induced toxicity. Pharmacology Researcher Perspectives 4:e00211.
França, L. R., and L. D. Russel. 1998. The testes of domestic animals. In Male Reproduction. A Multidisciplinary Overview, ed. J. R. R. Martinez-Garcia, 198-219. London: Churchill Livingstone.

Golub, M. S., M. S. Macintosh, and N. Baumrind. 1998. Developmental and reproductive toxicity of inorganic arsenic: Animal studies and human concerns. Journal of Toxicology and Environmental Health, Part B 1:199-237. doi:10.1080/10937409809524552.

Granger, D. N., and E. Senchenkova. 2010. Inflammation and the Microcirculation, 115-119. San Rafael, CA: Morgan \& Claypool Life Sciences.

Gupta, S., B. Bagel, S. Gujral, P. G. Subramanian, N. Khattry, H. Menon, and R. Nair. 2012. Parenthood in patients with acute promyelocytic leukemia after treatment with arsenic trioxide: A case series. Leukemia \& Lymphoma 53:21922194. doi:10.3109/10428194.2012.679936.

Guvvala, P. R., S. Sellappan, and R. J. Parameswaraiah. 2016. Impact of arsenic $(\mathrm{V})$ on testicular oxidative stress and sperm functional attributes in Swiss albino mice. Environmental Science and Pollution Research 23:1820018210. doi:10.1007/s11356-016-6870-3.

He, M., and L. Tan. 2015. Correlation between sperm ultrastructure in infertile patients with abnormal sperm morphology and DNA damage. Genetics and Molecular Research : GMR 14:17000-17006. doi:10.4238/2015. December.15.6.

Hu, H. T., Q. J. Yao, Y. L. Meng, H. L. Li, H. Zhang, J. P. Luo, C. Y. Guo, and X. Geng. 2016. Arsenic trioxide intravenous infusion combined with transcatheter arterial chemoembolization for the treatment of hepatocellular carcinoma with pulmonary metastasis: Long-term outcome analysis. Journal of Gastroenterology and Hepatology 32(2):295-300.

Kim, Y. J., and J. M. Kim. 2015. Arsenic toxicity in male reproduction and development. Development \& Reproduction 19:167-180. doi:10.12717/DR.2015.19.4.167.

King, Y. A., Y. J. Chiu, H. P. Chen, D. H. Kuo, C. C. Lu, and J. S. Yang. 2016. Endoplasmic reticulum stress contributes to arsenic trioxide-induced intrinsic apoptosis in human umbilical and bone marrow mesenchymal stem cells. Environmental Toxicology 31:314-328. doi:10.1002/ tox.22046.

Kleiman, N. J., A. M. Quinn, K. G. Fields, V. Slavkovich, and J. H. Graziano. 2016. Arsenite accumulation in the mouse eye. Journal of Toxicology and Environmental Health, Part A 79:339-341. doi:10.1080/15287394.2016.1151392.

Lamas, C. A., A. P. Gollucke, and H. Dolder. 2015. Grape juice concentrate $(\mathrm{G} 8000(\mathrm{R})$ intake mitigates testicular morphological and ultrastructural damage following cadmium intoxication. International Journal of Experimental Pathology 96:301-310. doi:10.1111/iep.12141.

Leite, R. P., F. S. Predes, J. C. Monteiro, K. M. Freitas, R. S. Wada, and H. Dolder. 2013. Advantage of guarana (Paullinia cupana Mart.) supplementation on cadmiuminduced damages in testis of adult Wistar rats. Toxicologic Pathology 41:73-79. doi:10.1177/0192623312447541. 
Leveque, D. 2014. Subcutaneous administration of anticancer agents. Anticancer Research 34:1579-1586.

Li, S. G., Y. S. Ding, Q. Niu, S. Z. Xu, L. J. Pang, R. L. Ma, M. X. Jing, G. L. Feng, J. M. Liu, and S. X. Guo. 2015. Grape seed proanthocyanidin extract alleviates arsenic-induced oxidative reproductive toxicity in male mice. Biomedical and Environmental Sciences : BES 28:272-280.

Li, S. G., S. Z. Xu, Q. Niu, Y. S. Ding, L. J. Pang, R. L. Ma, M. X. Jing, K. Wang, X. M. Ma, G. L. Feng, J. M. Liu, X. F. Zhang, H. L. Xiang, and F. Li. 2016. Lutein alleviates arsenic-induced reproductive toxicity in male mice via Nrf2 signaling. Human \& Experimental Toxicology 35:491-500. doi:10.1177/0960327115595682.

Li, Y., M. Wang, F. Piao, and X. Wang. 2012. Subchronic exposure to arsenic inhibits spermatogenesis and downregulates the expression of $\mathrm{ddx} 3 \mathrm{y}$ in testis and epididymis of mice. Toxicological Sciences 128:482-489. doi:10.1093/toxsci/kfs169.

Liu, S. H., R. S. Yang, Y. P. Yen, C. Y. Chiu, K. S. Tsai, and K. C. Lan. 2015. Low-concentration arsenic trioxide inhibits skeletal myoblast cell proliferation via a reactive oxygen species-independent pathway. PLoS One 10:e137907. doi:10.1371/journal.pone.0137907.

Lorenzo, H. K., S. A. Susin, J. Penninger, and G. Kroemer. 1999. Apoptosis inducing factor (AIF): A phylogenetically old, caspase-independent effector of cell death. Cell Death and Differentiation 6:516-524. doi:10.1038/sj.cdd.4400527.

Marettova, E., M. Maretta, and J. Legath. 2015. Toxic effects of cadmium on testis of birds and mammals: A review. Animal Reproduction Science 155:1-10. doi:10.1016/j. anireprosci.2015.01.007.

Mathews, V., E. Chendamarai, B. George, A. Viswabandya, and A. Srivastava. 2011. Treatment of acute promyelocytic leukemia with single-agent arsenic trioxide. Mediterranean Journal of Hematology and Infectious Diseases 3:e2011056. doi:10.4084/mjhid.2011.056.

Mathews, V., B. George, K. M. Lakshmi, A. Viswabandya, A. Bajel, P. Balasubramanian, R. V. Shaji, V. M. Srivastava, A. Srivastava, and M. Chandy. 2006. Single-agent arsenic trioxide in the treatment of newly diagnosed acute promyelocytic leukemia: Durable remissions with minimal toxicity. Blood 107:2627-2632. doi:10.1182/blood-2005-08-3532.

Mazumder, D. N., J. Gupta, A. Santra, A. Pal, A. Ghose, and S. Sarkar. 1998. Chronic arsenic toxicity in west Bengalthe worst calamity in the world. Journal of the Indian Medical Association 96 (4-7):18.

Meistrich, M. L., and R. A. Hess. 2013. Assessment of spermatogenesis through staging of seminiferous tubules. Meth Molecular Biologic 927:299-307.

Mohammad, A., S. A. Khan, P. Dubey, A. Nath, J. K. Singh, R. Kumar, and A. Kumar. 2013. Impact of arsenic on testosterone synthesis pathway and sperm production in mice. Innovative Journal Medica Health Sciences 3:185-189.

Morales, M. E., R. S. Derbes, C. M. Ade, J. C. Ortego, J. Stark, P. L. Deininger, and A. M. Roy-Engel. 2016. Heavy metal exposure influences double strand break DNA repair outcomes. PLoS One 11:e0151367. doi:10.1371/journal.pone.0151367.
Morales-Marin, M. E., E. J. Cordova, F. Centeno, A. Martinez-Hernandez, A. Mendez-Garcia, B. Molina, S. Frias, and L. Orozco. 2015. NFE2L2 gene variants and arsenic susceptibility: A lymphoblastoid model. Journal of Toxicology and Environmental Health, Part A 78:628-634. doi:10.1080/15287394.2015.1004146.

Mukhopadhyay, P. K., A. Dey, S. Mukherjee, and N. K. Pradhan. 2013. The effect of coadministration of alphatocopherol and ascorbic acid on arsenic trioxide-induced testicular toxicity in adult rats. Journal of Basic and Clinical Physiology and Pharmacology 24:245-253. doi:10.1515/jbcpp-2012-0039.

Nava-Hernandez, M. P., L. A. Hauad-Marroquin, S. BassolMayagoitia, G. Garcia-Arenas, R. Mercado-Hernandez, M. A. Echavarri-Guzman, and R. M. Cerda-Flores. 2009. Lead-, cadmium-, and arsenic-induced DNA damage in rat germinal cells. DNA and Cell Biology 28:241-248. doi:10.1089/dna.2009.0860.

Pandey, R., R. Kumar, S. P. Singh, D. K. Saxena, and S. P. Srivastava. 1999. Male reproductive effect of nickel sulphate in mice. Biometals 12:339-346. doi:10.1023/ A:1009291816033.

Pant, N., R. C. Murthy, and S. P. Srivastava. 2004. Male reproductive toxicity of sodium arsenite in mice. Human \& Experimental Toxicology 23:399-403. doi:10.1191/ 0960327104ht467oa.

Qin, D. Y., R. Huang, and T. Wu. 2008. In vitro arsenic trioxide induces apoptosis in $\mathrm{T}$ cells of asthmatic patients by a Bcl-2 related mechanism. Yao Xue Xue Bao = Acta Pharmaceutica Sinica 43:35-43.

Ratnaike, R. N. 2003. Acute and chronic arsenic toxicity. Postgraduate Medical Journal 79:391-396. doi:10.1136/ pmj.79.933.391.

Reagan-Shaw, S., M. Nihal, and N. Ahmad. 2008. Dose translation from animal to human studies revisited. The FASEB Journal 22:659-661. doi:10.1096/fj.07-9574LSF.

Rosenblatt, A. E., and K. L. Burnstein. 2009. Inhibition of androgen receptor transcriptional activity as a novel mechanism of action of arsenic. Molecular Endocrinology 23:412-421. doi:10.1210/me.2008-0235.

Sarkar, M., G. R. Chaudhuri, A. Chattopadhyay, and N. M. Biswas. 2003. Effect of sodium arsenite on spermatogenesis, plasma gonadotrophins and testosterone in rats. Asian Journal of Andrology 5:27-31.

Seed, J., R. E. Chapin, E. D. Clegg, L. A. Dostal, R. H. Foote, M. E. Hurtt, G. R. Klinefelter, S. L. Makris, S. D. Perreault, S. Schrader, D. Seyler, R. Sprando, K. A. Treinen, D. N. Veeramachaneni, and L. D. Wise. 1996. Methods for assessing sperm motility, morphology, and counts in the rat, rabbit, and dog: A consensus report. ILSI Risk Science Institute Expert Working Group on Sperm Evaluation. Reproductive Toxicology 10:237-244. doi:10.1016/08906238(96)00028-7.

Shah, M. A., A. Gupta, S. Kaur, and M. Gousuddin. 2012. A retrospective study of acute promyelocytic leukemia. IOSR Journal of Pharmacy 2:52-59. doi:10.9790/3013-26305259. 
Sharma, R. K., and A. Agarwal. 1996. Role of reactive oxygen species in male infertility. Urology 48:835-850. doi:10.1016/S0090-4295(96)00313-5.

Shen, Z. X., G. Q. Chen, J. H. Ni, X. S. Li, S. M. Xiong, Q. Y. Qiu, J. Zhu, W. Tang, G. L. Sun, K. Q. Yang, Y. Chen, L. Zhou, Z. W. Fang, Y. T. Wang, J. Ma, P. Zhang, T. D. Zhang, S. J. Chen, Z. Chen, and Z. Y. Wang. 1997. Use of arsenic trioxide (As2O3) in the treatment of acute promyelocytic leukemia (APL): II. Clinical efficacy and pharmacokinetics in relapsed patients. Blood 89:3354-3360.

Soignet, S. L., S. R. Frankel, D. Douer, M. S. Tallman, H. Kantarjian, E. Calleja, R. M. Stone, M. Kalaycio, D. A. Scheinberg, P. Steinherz, E. L. Sievers, S. Coutre, S. Dahlberg, R. Ellison, and R. P. Warrell, Jr. 2001. United States multicenter study of arsenic trioxide in relapsed acute promyelocytic leukemia. Journal of Clinical Oncology 19:3852-3860. doi:10.1200/JCO.2001.19.18.3852.

Soignet, S. L., P. Maslak, Z. G. Wang, S. Jhanwar, E. Calleja, L. J. Dardashti, D. Corso, A. DeBlasio, J. Gabrilove, D. A. Scheinberg, P. P. Pandolfi, and R. P. Warrell, Jr. 1998. Complete remission after treatment of acute promyelocytic leukemia with arsenic trioxide. The New England Journal of Medicine 339:1341-1348. doi:10.1056/ NEJM199811053391901.

Souza, A. C., S. C. Marchesi, R. P. Ferraz, G. D. Lima, J. A. De Oliveira, and M. Machado-Neves. 2016. Effects of sodium arsenate and arsenite on male reproductive functions in Wistar rats. Journal of Toxicology and Environmental Health, Part A 79:274-286. doi:10.1080/15287394.2016.1150926.

Stanton, P. G. 2016. Regulation of the blood-testis barrier. Seminars in Cell \& Developmental Biology 59:166-173. doi:10.1016/j.semcdb.2016.06.018.

Stein, E. M., and M. S. Tallman. 2012. Does arsenic trioxide impact fertility? Leukemia \& Lymphoma 53:2099-2100. doi:10.3109/10428194.2012.685737.

Susin, S. A., H. K. Lorenzo, N. Zamzami, I. Marzo, B. E. Snow, G. M. Brothers, J. Mangion, E. Jacotot, P. Costantini, M. Loeffler, N. Larochette, D. R. Goodlett, R. Aebersold, D. P. Siderovski, J. M. Penninger, and G. Kroemer. 1999. Molecular characterization of mitochondrial apoptosis-inducing factor. Nature 397:441-446. doi:10.1038/17135.

Testi, A. M., M. D’Angio, F. Locatelli, A. Pession, and F. Lo Coco. 2014. Acute promyelocytic leukemia (APL): Comparison between children and adults. Mediterranean
Journal of Hematology and Infectious Diseases 6:e2014032. doi:10.4084/mjhid.2014.032.

Thomas, D. J., M. Styblo, and S. Lin. 2001. The cellular metabolism and systemic toxicity of arsenic. Toxicology and Applied Pharmacology 176:127-144. doi:10.1006/ taap.2001.9258.

Tsai, M. Y., S. D. Yeh, R. S. Wang, S. Yeh, C. Zhang, H. Y. Lin, C. R. Tzeng, and C. Chang. 2006. Differential effects of spermatogenesis and fertility in mice lacking androgen receptor in individual testis cells. Proceedings of the National Academy of Sciences 103:18975-18980. doi:10.1073/pnas.0608565103.

Tsai, S. M., T. N. Wang, and Y. C. Ko. 1998. Cancer mortality trends in a blackfoot disease endemic community of Taiwan following water source replacement. Journal of Toxicology and Environmental Health, Part A 55:389-404. doi:10.1080/009841098158322.

Walker, A. M., J. J. Stevens, K. Ndebele, and P. B. Tchounwou. 2016. Evaluation of arsenic trioxide potential for lung cancer treatment: Assessment of apoptotic mechanisms and oxidative damage. Journal of Cancer Science \& Therapy 8:1-9. doi:10.4172/1948-5956.1000379.

Weibel, E. R. 1963. Principles and methods for the morphometric study of the lung and other organs. Laboratory Investigation 12:131-155.

Xia, Y., G. Hao, and Y. Yang. 2009. Study on reproductive and immune toxicity of male rats exposed to As2O3. Wei Sheng Yan Jiu = Journal of Hygiene Research 38:720-722.

Yanada, M., S. Yano, H. Kanamori, M. Gotoh, N. Emi, K. Watakabe, M. Kurokawa, A. Nishikawa, T. Mori, N. Tomita, M. Murata, H. Hashimoto, H. Henzan, Y. Kanda, M. Sawa, A. Kohno, Y. Atsuta, T. Ichinohe, and A. Takami. 2017. Autologous hematopoietic cell transplantation for acute promyelocytic leukemia in second complete remission: Outcomes before and after the introduction of arsenic trioxide. Leukemia \& Lymphoma 58(5): 1061-1067.

Zhang, X. Y., S. M. Yang, H. P. Zhang, Y. Yang, S. B. Sun, J. P. Chang, X. C. Tao, T. Y. Yang, C. Liu, and Y. M. Yang. 2015. Endoplasmic reticulum stress mediates the arsenic trioxide-induced apoptosis in human hepatocellular carcinoma cells. The International Journal of Biochemistry \& Cell Biology 68:158-165. doi:10.1016/j. biocel.2015.09.009. 